\title{
Changes in the Residents' Consciousness due to Environmental Improvements After Consolidation of Municipalities
}

\author{
Takashi Hashimoto $^{1}$, Akira Yuzawa ${ }^{2}$, Tetsuo Morita ${ }^{3}$ and Shinya Tsukada ${ }^{4}$ \\ ${ }^{1}$ Isesaki City Office, ${ }^{2}$ Maebashi Institute of Technology, Japan \\ ${ }^{3}$ Gunma National College of Technology, ${ }^{4}$ Maebashi City Office, Japan
}

\begin{abstract}
The purpose of this paper is to clarify the changes in the consciousness of residents due to environmental improvements after consolidation of municipalities. The focus of this research is to quantify both “increases in residents' satisfaction" and the "increased sense of unity in residents' consciousness" due to environmental improvements during the four years after consolidation. The city analyzed is Isesaki City, Gunma Prefecture, Japan, which has already carried out consolidation. In analyzing residents' consciousness, we performed factor analysis and covariance structural analysis using the results of surveys of residents' consciousness. The results of the analysis showed that (1) residents' satisfaction has increased, but (2) the sense of unity in residents' consciousness has not increased. This paper is intended to suggest that (1) residents' satisfaction can be increased by improving the environment for four years after consolidation, and (2) increasing the sense of unity in residents' consciousness by improving the environment for four years after consolidation is extremely difficult.
\end{abstract}

Keywords: Consolidation of municipalities, Environmental improvement, Residents’ consciousness, Factor analysis, Covariance structural analysis

\section{INTRODUCTION}

In Japan, the consolidation of municipalities through mergers of cities, towns, and villages is progressing. The main goal of this consolidation is for the government to effectively address the broad array of residents' demands. A newly merged municipality can govern more broadly and efficiently as a result of the choices and support of a greater number of residents. In addition, the residents living in the merged municipality can participate in community design from a broader perspective.

Against this backdrop, the number of municipalities in Japan has drastically reduced, from 3,232 in March 1999 to 1,727 in March 2011. Many merged municipalities demonstrate an increase in resident satisfaction and in unity of residents' consciousness. Several papers regarding these issues have already been published.

Okusawa et al [1] argues the importance of continual study of city planning among merged municipalities that were enlarged through the consolidation of several municipalities. Hashimoto and Yuzawa [2] makes clear that regional differences in residents' consciousness are arising due to discontinuous city planning among merged municipalities. Endo et al [3] makes clear the deep connection between a municipality's name and its residents' sense of belonging, and the barrier that sense of belonging can pose to forming a sense of unity. Hashimoto and Yuzawa [4] argues the importance of city planning that responds to regional differences that arise in merged municipalities not only in residents' consciousness, but in the consciousness of the municipalities as well.

In the midst of these developments, the Ministry of Internal Affairs and Communications [5] has published the changes in residents' consciousness following the consolidation of municipalities, based on the results of a national survey of residents. This literature shows that simply consolidating, without environmental improvements that residents can feel, will not result in an increase in resident satisfaction or unity of residents' consciousness. Furthermore, this literature shows that to increase the unity of residents' consciousness following consolidation takes years, even decades.

However, the undertaking of environmental improvements throughout the merged municipality also appears to affect resident satisfaction and unity of residents' consciousness. Feeling improvements in the environment, especially improvements in green spaces and parks that are closely connected to everyday life, appears to change residents' consciousness. Research using covariance structure analysis from the perspective of the environment and resident consciousness has already been published [6]-[8]. Among these publications, Tsukada and Yuzawa [6], [7] makes clear that park amenities greatly influence residents' consciousness. Tsukada et al [9] also explains that, when evaluating parks, it is important to focus on residents' use of the park after improvement.

From the above research, it can be hypothesized that environmental improvements throughout a merged municipality can increase residents' satisfaction and unity of residents' consciousness. Therefore, research that quantifies the changes in residents' consciousness due to environmental improvements throughout a merged municipality is required. However, research that continually surveys residents' consciousness following consolidation and quantifies the changes is not being conducted.

Therefore, the goal of this research is to quantify the changes in residents' consciousness due to environmental improvements following consolidation. For the subject of this research, we chose Isesaki City in Gunma Prefecture, which satisfies the conditions necessary for a subject of this research because (1) it is a merged municipality, (2) it has actively promoted environmental improvements following the consolidation, and (3) over four years have passed since the consolidation, making it possible to analyze the long-term changes in residents' consciousness due to environmental improvements after consolidation of municipalities. Isesaki City consolidated one city, two towns, and one village on January 1, 2005. 


\section{RESEARCH METHOD}

\subsection{Research Flow}

Fig. 1 shows the research flow of this paper.

First, in order to make clear the changes in residents' consciousness that is the goal of this research, two surveys were conducted, one at the time of consolidation (in 2005), and another four years later (in 2009).

In the first analysis, we conduct a factor analysis and covariance structural analysis using the data gained from responses to the surveys (980 responses), and determine the factors of residents' subconscious and a structural model of residents' consciousness.

In the second analysis, we analyze changes in residents' consciousness using path coefficients gained from the results of the covariance structural analysis. This analysis method uses path coefficients to calculate an evaluation score based on the data from each survey (494 responses in 2005; 486 responses in 2009), and analyzes the mean value and variation coefficient of the evaluation score of each factor. Increase of the mean value of the evaluation score can be evaluated as increase in residents' satisfaction. Decrease of the variation coefficient of the evaluation score means a reduction in variability and can be evaluated as increase in the sense of unity in residents' consciousness. From the results of these analyses, we then consider the changes in residents' consciousness post-consolidation.

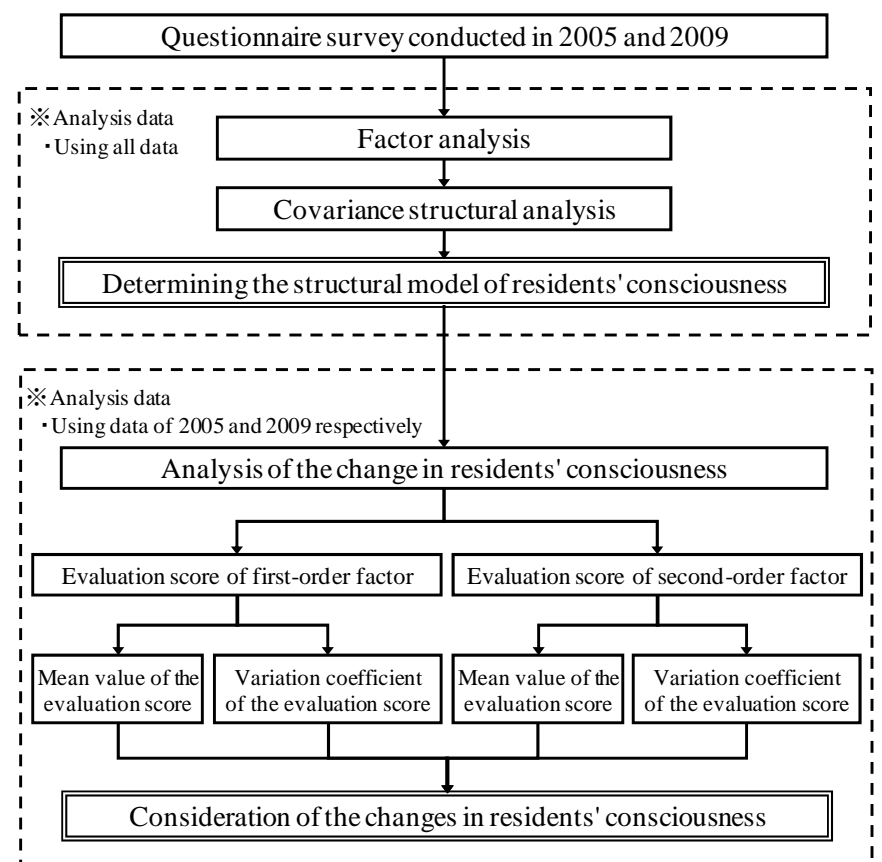

Fig. 1 Research Flow

Table 1 Overall Overview of the Survey

\begin{tabular}{c|ccc}
\hline & 2005 Survey & 2009 Survey & Total \\
\hline \hline Survey Distribution Period & $1 / 15 / 2005$ to $1 / 20 / 2005$ & $1 / 10 / 2009$ to $1 / 15 / 2009$ & - \\
Number of Surveys Distributed & 4,000 & 4,000 & 8,000 \\
Number of Responses & 494 & 486 & 980 \\
Response Rate (\%) & 12.4 & 12.2 & 12.3 \\
\hline Subjects of Survey & residents of households within a 1.0km radius of the research area \\
Survey Method & surveys distributed in research area, and collected by postal mail \\
Survey Contents & individual attributes, with five levels of resident satisfaction \\
\hline
\end{tabular}

\subsection{Surveys}

The overall overview of the survey and the overview of the survey area are displayed in Tables 1 and 2, respectively. The response rate of the surveys is displayed in Table 1, with the response rate for both the 2005 and 2009 surveys at approximately 12 percent. So that no biases among survey respondents would occur, the survey area covered the 10 areas listed in Table 2. These 10 areas can be sorted by former municipality into former Isesaki City (areas 1 through 5), former Sakai Town (areas 6 and 7), former Azuma Village (areas 8 and 9), and former Akabori Town (area 10). Four hundred households were chosen at random from survey areas 1 through 10 as targets of the surveys. Survey responses were collected by postal mail.

The evaluation items of the survey consisted of 25 items that have a deep connection to the overall evaluation of a city, and are listed in Table 3 . Survey respondents evaluated each item on a scale of 1 to 5 (1=dissatisfied; $2=$ slightly dissatisfied; $3=$ normal; $4=$ =slightly satisfied; $5=$ satisfied).

Table 2 Overview of the Survey Area

\begin{tabular}{|c|c|c|c|c|c|c|c|}
\hline \multirow{2}{*}{$\begin{array}{c}\text { Former } \\
\text { Municipalities }\end{array}$} & \multirow{2}{*}{$\begin{array}{c}\text { Research } \\
\text { Area }\end{array}$} & \multicolumn{3}{|c|}{2005 Survey } & \multicolumn{3}{|c|}{2009 Survey } \\
\hline & & \begin{tabular}{|c|} 
Distribution \\
Number
\end{tabular} & $\begin{array}{l}\text { Number of } \\
\text { Responses }\end{array}$ & $\begin{array}{l}\text { Response } \\
\text { Rate (\%) }\end{array}$ & \begin{tabular}{|c|} 
Distribution \\
Number
\end{tabular} & $\begin{array}{l}\text { Number of } \\
\text { Responses }\end{array}$ & $\begin{array}{l}\text { Response } \\
\text { Rate (\%) }\end{array}$ \\
\hline \multirow{5}{*}{$\begin{array}{c}\text { Former } \\
\text { Isesaki City }\end{array}$} & 1 & 400 & 62 & 15.5 & 400 & 40 & 10.0 \\
\hline & 2 & 400 & 48 & 12.0 & 400 & 40 & 10.0 \\
\hline & 3 & 400 & 45 & 11.3 & 400 & 43 & 10.8 \\
\hline & 4 & 400 & 41 & 10.3 & 400 & 55 & 13.8 \\
\hline & 5 & 400 & 62 & 15.5 & 400 & 68 & 17.0 \\
\hline \multirow{2}{*}{$\begin{array}{c}\text { Former } \\
\text { Sakai Town }\end{array}$} & 6 & 400 & 54 & 13.5 & 400 & 40 & 10.0 \\
\hline & 7 & 400 & 48 & 12.0 & 400 & 55 & 13.8 \\
\hline \multirow{2}{*}{$\begin{array}{c}\text { Former } \\
\text { Azuma Village }\end{array}$} & 8 & 400 & 39 & 9.8 & 400 & 47 & 11.8 \\
\hline & 9 & 400 & 38 & 9.5 & 400 & 44 & 11.0 \\
\hline $\begin{array}{c}\text { Former } \\
\text { Akabori Town }\end{array}$ & 10 & 400 & 57 & 14.3 & 400 & 54 & 13.5 \\
\hline
\end{tabular}

Table 3 Evaluation Items of the Surveys

\begin{tabular}{ll}
$\begin{array}{c}\text { Evaluation } \\
\text { Item }\end{array}$ & \multicolumn{1}{c}{ Contents of the Evaluation Item } \\
\hline A1 & provide administrative services that meet the demands of residents \\
A2 & ease of use of city hall and city branch offices \\
A3 & health of public finances \\
A4 & ease of obtaining government information \\
A5 & opportunities to participate in community design \\
\hline A6 & enhancement of the content of primary education \\
A7 & enhancement of kindergartens and preschools \\
A8 & improvement of school facilities \\
A9 & enhancement of universities, junior colleges, vocational schools \\
A10 & places and opportunities for lifelong learning \\
\hline A11 & vibrant commercial districts and shopping centers \\
A12 & securing places of employment by attracting industry \\
A13 & ease of use of leisure and entertainment facilities \\
A14 & convenience of daily shopping \\
A15 & support for revitalizing agriculture \\
\hline A16 & protection of green space and nature \\
A17 & connection to water through improvement of rivers and ponds \\
A18 & improvement and ease of use of parks \\
A19 & improvement of city landscape \\
A20 & environmental measures to reduce noise, vibration, and air pollution \\
\hline A21 & improvement of local roads \\
A22 & improvement of arterial roads \\
A23 & safe passage of pedestrians and cyclists \\
A24 & ease of use of railways \\
A25 & ease of use of buses \\
\hline
\end{tabular}




\section{ENVIRONMENTAL IMPROVEMENT POLICY}

Isesaki City is located in central Japan in southern Gunma Prefecture, as shown in Fig. 2. As can be seen from Fig. 2, the city has abundant rivers and parks.

Before consolidation, Isesaki City was former Isesaki City, former Sakai Town, former Azuma Village, and former Akabori Town. At the time of consolidation, the city's area was 13,933 hectares, and the population was 207,000, as shown in Table 4. In order to increase resident satisfaction and unity of residents' consciousness following the consolidation, Isesaki City pursued a policy of environmental improvement. This policy consisted mainly of the following five items (A) through (E):

(A) Increased Park Space (Table 4)

During the four years from 2005 to 2009, Isesaki City increased its park space from 96 hectares to 127 hectares. This increase was largely the result of the completion of the Consolidation Memorial Park, discussed next.

(B) Creation of Consolidation Memorial Park (Fig. 3) Isesaki City created Consolidation Memorial Park from 20 hectares of former ponds and green space. The park was located near a highway and parking area for visitor convenience.

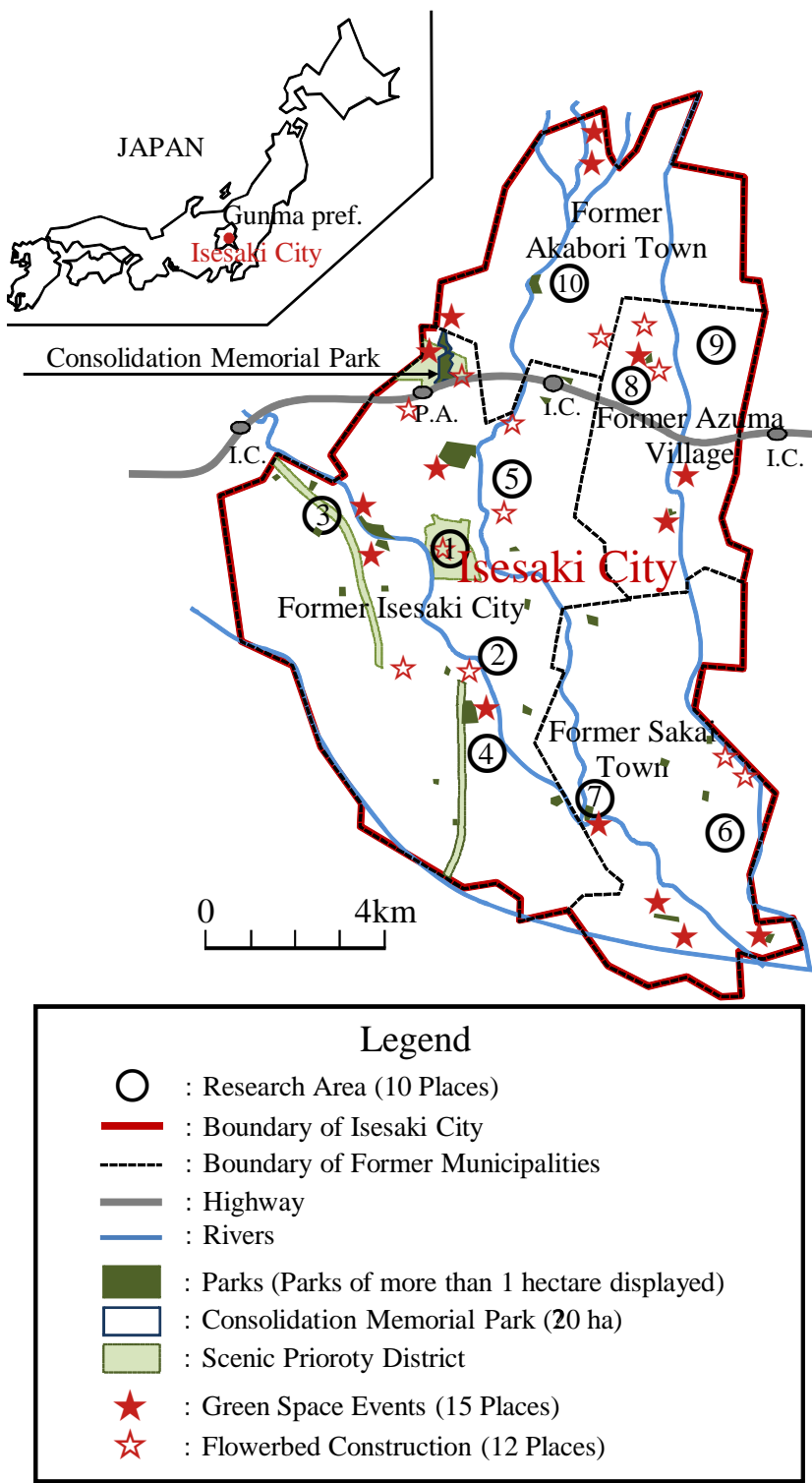

Fig. 2 Research Area (10 Places)
(C) Creation of a Scenic Priority District (Fig. 4)

Isesaki City designated Consolidation Memorial Park and surrounding areas a scenic priority district, and carried out scenic improvement projects. The main goal of these projects was to increase hospitality towards visitors through improvements such as benches at scenic spots.

(D) Green Space Events (Fig. 5)

Isesaki City and its residents carried out greening events throughout the consolidated city. These events took place from March to November 2008. Their locations are marked in Fig. 2 as $\star$ (15 in all), and they promoted interaction among different regions throughout the city. The events consisted not only of interacting with the natural environment, but also of presentations by children and introductions of traditional crafts by the elderly, thus promoting interaction between generations.

(E) Flowerbed Construction (Fig. 6)

Isesaki City and its residents constructed flowerbeds at parks and open spaces throughout the city. Their locations are marked in Fig. 2 as $i$ (12 in all), and described in Fig. 6. Through such resident volunteer activities, the city promoted environmental improvement through greening in areas other than parks such as open spaces.

In these ways, post-consolidation Isesaki City and its residents actively promoted environmental improvement throughout the merged municipality.

Table 4 Increase in Park Space Area (A)

\begin{tabular}{c|cc|cc}
\hline \multicolumn{3}{c|}{ Scale of Municipalities at the time of the Merger } & At Year 2005 & At Year 2009 \\
\hline Former Municipalities & $\begin{array}{c}\text { Area } \\
\text { (ha) }\end{array}$ & $\begin{array}{c}\text { Population } \\
\text { (Thousands) }\end{array}$ & $\begin{array}{c}\text { Park Space Area } \\
\text { (ha) }\end{array}$ & $\begin{array}{c}\text { Park Space Area } \\
\text { (ha) }\end{array}$ \\
\hline \hline Former Isesaki City & 6,517 & 134 & 82 & 106 \\
Former Sakai Town & 3,126 & 31 & 10 & 13 \\
Former Azuma Village & 2,438 & 23 & 0 & 4 \\
Former Akabori Town & 1,852 & 19 & 4 & 127 \\
\hline Total & 13,933 & 207 & 96 & (n) \\
\hline
\end{tabular}

Fig. 3 Creation of Consolidation Memorial Park (B)
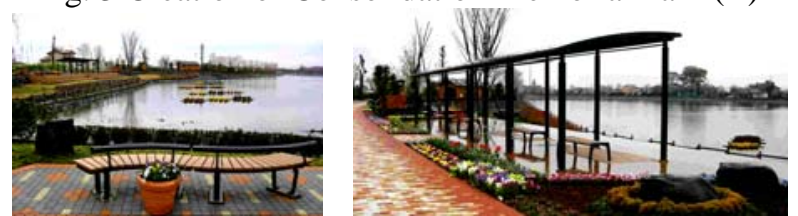

Fig. 4 Creation of a Scenic Priority District (C)

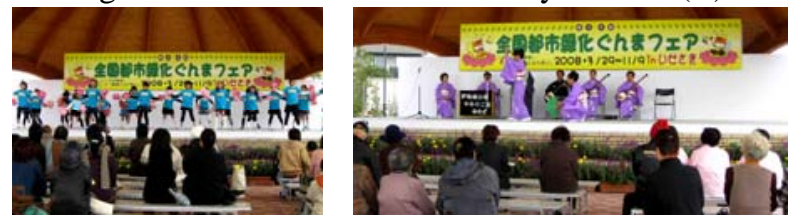

Fig. 5 Green Space Events (D)

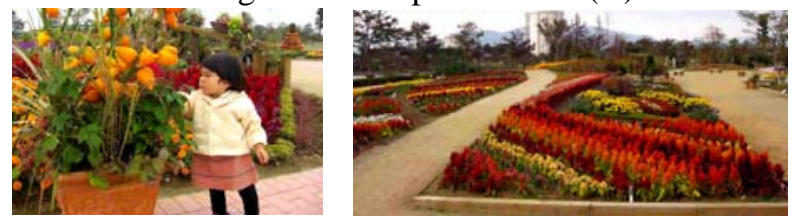

Fig. 6 Flowerbed Construction (E) 


\section{CONSTRUCTING A STRUCTURAL MODEL OF RESIDENTS' CONSCIOUSNESS}

\subsection{Results and Consideration of the Factor Analysis}

In the factor analysis, we extracted factors from the response data in order to understand the residents' subconscious.

Table 5 displays the results of the factor loadings, eigenvalue, cumulative contribution rate, and factor definitions gained through the factor analysis. The first factor is defined as "Government" due to the large weight given to the needs of residents, city hall, public finance, government information, and resident participation. Similarly, the second factor is defined as "Education," the third as "Industry," the fourth as "Environment," and the fifth as "Transportation."

\subsection{Determining the Structural Model of Residents' Consciousness}

The results of the factor analysis make clear the five factors of the residents' subconscious. In the following analysis, we determine the structural model of the residents' consciousness in the merged municipality, and conduct a covariance structural analysis using the survey response data to quantify the importance of each factor.

Fig. 7 shows the path diagram of the covariance structural analysis model used in this analysis. The first-order factor of Fig. 7 consists of the five factors extracted using the factor analysis, and establishes a second-order factor model that makes a "Comprehensive Evaluation" from the second-order factor.

Table 6 represents the results of the covariance structural analysis conducted using the path diagram of Fig. 7. The t-value of path coefficients $P k$ and $P k n$ all satisfy a $1 \%$ significance level, and the GFI (Goodness of Fit Index) was a satisfactory 0.873 .

Table 5 Results of Factor Analysis (after Varimax Rotation)

\begin{tabular}{|c|c|c|c|c|c|c|}
\hline \multicolumn{2}{|c|}{ Evaluation Item } & Factor1 & Factor2 & Factor3 & Factor4 & Factor5 \\
\hline \multirow{25}{*}{$\begin{array}{l}\text { Factor } \\
\text { Loadings }\end{array}$} & A1 & 0.780 & 0.223 & 0.055 & 0.135 & 0.260 \\
\hline & A2 & 0.722 & 0.152 & 0.076 & 0.122 & 0.286 \\
\hline & A3 & 0.674 & 0.184 & 0.083 & 0.190 & 0.265 \\
\hline & A4 & 0.653 & 0.242 & 0.217 & 0.214 & -0.031 \\
\hline & A5 & 0.589 & 0.201 & 0.315 & 0.145 & -0.132 \\
\hline & A6 & 0.194 & 0.761 & 0.066 & 0.190 & 0.147 \\
\hline & A7 & 0.096 & 0.746 & 0.041 & 0.131 & 0.191 \\
\hline & A8 & 0.229 & 0.708 & 0.117 & 0.111 & 0.205 \\
\hline & A9 & 0.141 & 0.663 & 0.210 & 0.044 & 0.083 \\
\hline & A10 & 0.337 & 0.489 & 0.251 & 0.263 & -0.007 \\
\hline & A11 & 0.136 & 0.101 & 0.706 & 0.102 & 0.157 \\
\hline & A12 & 0.142 & 0.142 & 0.695 & 0.157 & 0.128 \\
\hline & A13 & 0.158 & 0.234 & 0.678 & 0.222 & 0.135 \\
\hline & A14 & 0.000 & 0.049 & 0.635 & 0.154 & 0.288 \\
\hline & A15 & 0.334 & -0.039 & 0.375 & 0.195 & 0.028 \\
\hline & A16 & 0.234 & 0.105 & 0.198 & 0.787 & 0.097 \\
\hline & A17 & 0.220 & 0.159 & 0.138 & 0.786 & 0.081 \\
\hline & A18 & 0.105 & 0.160 & 0.243 & 0.717 & 0.202 \\
\hline & A19 & 0.147 & 0.168 & 0.409 & 0.446 & 0.325 \\
\hline & A20 & 0.291 & 0.218 & 0.060 & 0.438 & 0.301 \\
\hline & A21 & 0.087 & 0.135 & 0.189 & 0.345 & 0.709 \\
\hline & A22 & 0.052 & 0.083 & 0.154 & 0.302 & 0.709 \\
\hline & A23 & 0.217 & 0.279 & 0.261 & 0.114 & 0.572 \\
\hline & A24 & 0.248 & 0.230 & 0.323 & -0.166 & 0.527 \\
\hline & A25 & 0.206 & 0.279 & 0.433 & -0.012 & 0.434 \\
\hline \multicolumn{2}{|c|}{ Eigenvalue } & 3.146 & 2.984 & 2.981 & 2.811 & 2.539 \\
\hline \multicolumn{2}{|c|}{\begin{tabular}{c|} 
Cumulative \\
Contribution Rate
\end{tabular}} & 12.58 & 24.52 & 36.44 & 47.69 & 57.84 \\
\hline \multicolumn{2}{|c|}{$\begin{array}{l}\text { Definition of } \\
\text { Factors }\end{array}$} & Government & Education & Industry & Environment & Transportation \\
\hline
\end{tabular}

From these results, we judged the path diagram of Fig. 7 to be a highly reliable model of residents' consciousness.

In addition, the $P k$ values from Table 6 were, from largest to smallest, 2.262 for Transportation, 2.190 for Environment, 2.110 for Education, 1.590 for Government, and 1.000 for Industry. From these results, it is clear that the Comprehensive Evaluation of residents' consciousness is largely influenced by Transportation, followed by Environment.

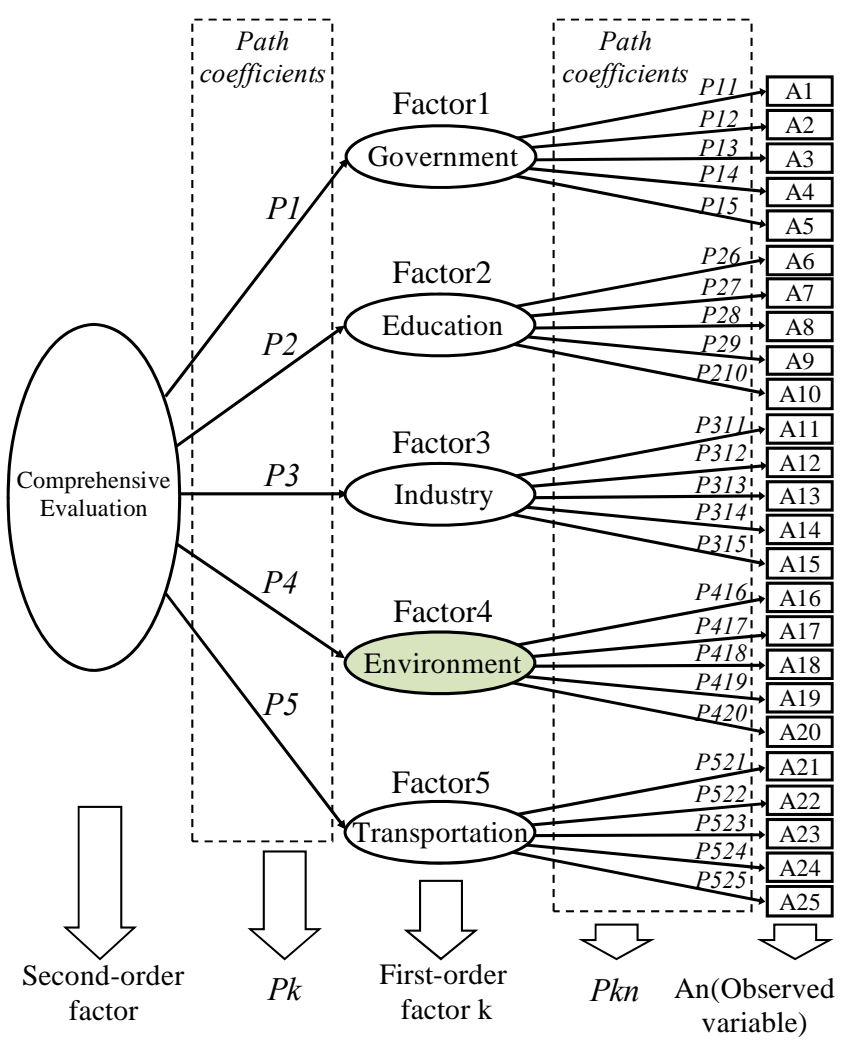

Fig. 7 Covariance Structural Analysis Model

(Path Diagram)

Table 6 Results of Covariance Structural Analysis

\begin{tabular}{|c|c|c|c|c|c|c|c|c|c|}
\hline $\begin{array}{l}\text { Second-order } \\
\text { factor }\end{array}$ & $P k$ & $\begin{array}{l}\text { First-order } \\
\text { factor k }\end{array}$ & $P k n$ & $\begin{array}{c}\text { Observed } \\
\text { variable }\end{array}$ & $P k \times P k n$ & $\alpha_{j}$ & $\Sigma \alpha$ & $\beta_{j}$ & $\Sigma \beta_{j}$ \\
\hline \multirow{25}{*}{$\begin{array}{l}\text { Comprehensive } \\
\text { Evaluation }\end{array}$} & \multirow{5}{*}{1.590} & \multirow{5}{*}{ Government } & 1.542 & $\overline{\mathrm{A} 1}$ & 2.452 & 23.7 & \multirow{5}{*}{100} & "4.7 & \multirow{25}{*}{100} \\
\hline & & & 1.506 & A2 & 2.395 & 23.2 & & 4.6 & \\
\hline & & & 1.279 & A3 & 2.034 & 19.7 & & 3.9 & \\
\hline & & & 1.175 & A4 & 1.868 & 18.1 & & 3.6 & \\
\hline & & & 1.000 & A5 & 1.590 & 15.4 & & 3.1 & \\
\hline & \multirow{5}{*}{2.110} & \multirow{5}{*}{ Education } & 0.986 & A6 & 2.080 & 20.9 & \multirow{5}{*}{100} & 4.0 & \\
\hline & & & 1.000 & A7 & 2.110 & 21.2 & & 4.1 & \\
\hline & & & 0.993 & A8 & 2.095 & 21.0 & & 4.0 & \\
\hline & & & 0.878 & A9 & 1.853 & 18.6 & & 3.6 & \\
\hline & & & 0.861 & A10 & 1.817 & 18.2 & & 3.5 & \\
\hline & \multirow{5}{*}{1.000} & \multirow{5}{*}{ Industry } & 2.138 & A11 & 2.138 & 22.4 & \multirow{5}{*}{100} & 4.1 & \\
\hline & & & 1.954 & A12 & 1.954 & 20.4 & & 3.8 & \\
\hline & & & 2.236 & A13 & 2.236 & 23.4 & & 4.3 & \\
\hline & & & 2.231 & A14 & 2.231 & 23.3 & & 4.3 & \\
\hline & & & 1.000 & A15 & 1.000 & 10.5 & & 1.9 & \\
\hline & \multirow{5}{*}{2.190} & \multirow{5}{*}{ Environment } & 1.102 & A16 & 2.413 & 23.5 & \multirow{5}{*}{100} & 4.6 & \\
\hline & & & 1.000 & A17 & 2.190 & 21.3 & & 4.2 & \\
\hline & & & 1.073 & A18 & 2.350 & 22.8 & & 4.5 & \\
\hline & & & 0.834 & A19 & 1.826 & 17.7 & & 3.5 & \\
\hline & & & 0.690 & A20 & 1.511 & 14.7 & & 2.9 & \\
\hline & \multirow{5}{*}{2.262} & \multirow{5}{*}{ Transportation } & 1.172 & A21 & 2.651 & 22.5 & \multirow{5}{*}{100} & 5.1 & \\
\hline & & & 1.000 & A22 & 2.262 & 19.2 & & 4.4 & \\
\hline & & & 1.015 & A23 & 2.296 & 19.5 & & 4.4 & \\
\hline & & & 0.959 & A24 & 2.169 & 18.4 & & 4.2 & \\
\hline & & & 1.063 & A25 & 2.405 & 20.4 & & 4.6 & \\
\hline
\end{tabular}

Number of Samples=980, GFI=0.873, AGFI=0.847, $(P k, P k n: 1 \%$ significance level $)$ 
In addition, the $P k n$ values from Table 6 were, from largest to smallest, 1.102 for protection of green space and nature, 1.073 for improvement and ease of use of parks, 1.000 for connection to water through improvement of rivers and ponds, 0.834 for improvement of city landscape, and 0.690 for environmental measures to reduce noise, vibration, and air pollution. From these results, it is clear that the residents' consciousness of the Environment is largely influenced by protection of green space and nature, followed by improvement and ease of use of parks.

Furthermore, Table 6 uses path coefficients $P k$ and $P k n$, derived from the results of the covariance structural analysis, to calculate parameter $\alpha_{j}$, the first-order factor of each observed variable, and parameter $\beta_{j}$, the second-order factor of each observed variable. The equations for calculating $\alpha_{j}$ and $\beta_{j}$ are as shown in items (1) and (2) below.

$\alpha_{j}=\frac{P k n}{\sum P k n} \times 100(\%)$

$\beta_{j}=\frac{P k \times P k n}{\sum(P k \times P k n)} \times 100(\%)$

Parameters $\alpha_{j}$ and $\beta_{j}$ express, as a percentage, the influence that each observed variable has on the first-order factor and second-order factor. This research attempts to analyze the evaluation score of the residents' consciousness using parameters $\alpha_{j}$ and $\beta_{j}$ and the observed variables.

\section{ANALYSIS OF THE CHANGE IN RESIDENTS' CONSCIOUSNESS}

\subsection{Analysis of the Evaluation Score of the First-Order Factor and Second-Order Factor}

The evaluation score analysis takes the five-step evaluation of parameters $\alpha_{j}$ and $\beta_{j}$ and the observed variables, divides it by 5 to arrive at $X_{j}$, then calculates the evaluation score of each survey respondent for the first-order factor $\left(\alpha_{j} \times X_{j}\right)$ and second-order factor $\left(\beta_{j} \times X_{j}\right)$.

The reason for converting the observed variables into $X_{j}$ is to make the evaluation score of the first-order and second-order factors a full 100 for responses with a "5" rating given for each item.

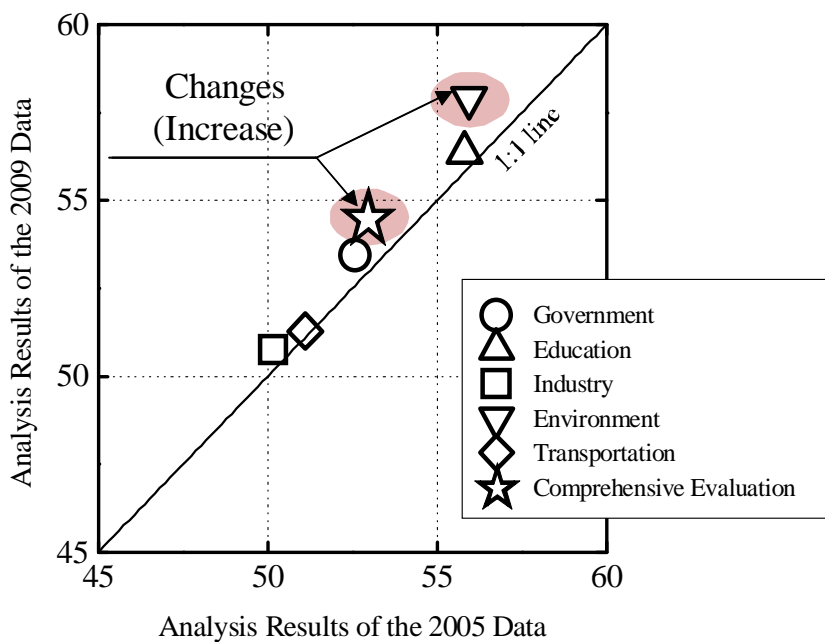

Fig. 8 Mean Value of the Evaluation Score
Thus, the equations for calculating the evaluation score $Y_{i}$ of the first-order factor $\mathrm{k}$ for each survey respondent, and for calculating the evaluation score $Z$ of the second-order factor, are (3) and (4), respectively.

$Y_{i}=\sum_{j=1}^{m}\left(\alpha_{j} \times X_{j}\right)$
$Z=\sum_{j=1}^{n}\left(\beta_{j} \times X_{j}\right)$

$Y_{i}$ : Evaluation Score of the First-Order Factor (max 100)

$Z$ : Evaluation Score of the Comprehensive Evaluation (max 100)

$X_{j}:$ 5-Step Evaluation of the Observed Variables $\div 5$

$m$ : Number of Evaluation Items of the First-Order Factor $\mathrm{k}$ $n$ : Number of All Evaluation Items

Next, we quantify the mean value and variation coefficient of the evaluation score of the data from each survey (the first-order factor being $\alpha_{j} \times X_{j}$, and second-order factor being $\beta_{j} \times X_{j}$ ).

Figures 8 and 9 display the mean value and variation coefficient of each evaluation score. Both figures display the analysis results of the 2005 data on the horizontal axis, and the analysis results of the 2009 data on the vertical axis, with a 1:1 line drawn for reference.

In Fig. 8, only plots where the results of the independent t-test satisfied a 5\% significance level were labeled "Changes.” In Fig. 9, only plots where the results of the test of variance homogeneity satisfied a 5\% significance level were labeled "Changes." The plots labeled "Changes" in both figures represent not only qualitative changes of being above or below the 1:1 line, but also statistical changes.

\subsection{Consideration of the Changes in Residents' Consciousness}

The following considers the changes in residents' consciousness using the results of Figures 8 and 9 .

(A) Mean Value of the Evaluation Score (Fig. 8)

The mean value of the evaluation score of the first-order factor "Environment" and the second-order factor “Comprehensive Evaluation" increased. Consequently, during the 4 years following the consolidation of Isesaki City, residents' satisfaction in "Environment" and "Comprehensive Evaluation” increased.

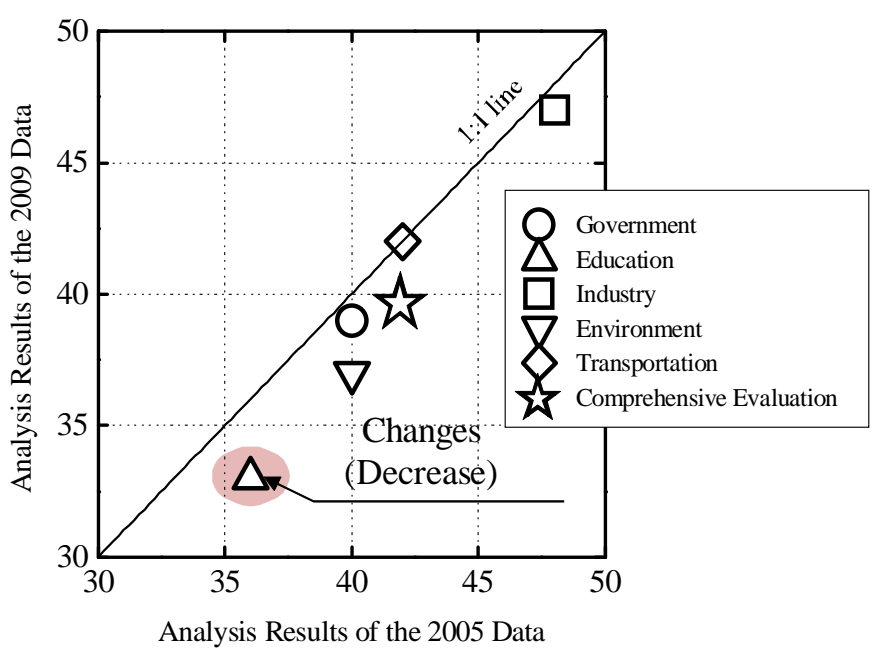

Fig. 9 Variation Coefficient of the Evaluation Score 
(B) Variation Coefficient of the Evaluation Score (Fig. 9) The variation coefficient of the evaluation score of the first-order factor "Education" decreased. The evaluation score of the variation coefficient of the first-order factor "Environment" and the second-order factor "Comprehensive Evaluation" did not display a statistical change. Consequently, during the 4 years following the consolidation of Isesaki City, the unity of residents' consciousness towards "Education" increased, but the unity of residents' consciousness towards "Environment” and “Comprehensive Evaluation” did not increase.

\section{CONCLUSION}

This research has sought to quantify changes in the consciousness of Isesaki City residents due to environmental improvements throughout Isesaki City using data from surveys conducted at the time of consolidation (in 2005) and four years after consolidation (in 2009). The conclusions from the results of this research is as follows.

(A) Isesaki City and its residents were able to increase residents" satisfaction in "Environment" by promoting environmental improvements throughout the merged municipality. Therefore, it is possible to increase residents' satisfaction in the environment by carrying out environmental improvements throughout a merged municipality with the cooperation of city residents.

(B) Isesaki City and its residents were able to increase residents" satisfaction in "Comprehensive Evaluation" through increases in residents' satisfaction in "Environment" by promoting environmental improvements throughout the merged municipality. We reached this conclusion because the mean value of the evaluation score of only "Environment" and “Comprehensive Evaluation" increased during the 4 years after consolidation. Furthermore, because the value of first-order factor $P k$ for "Environment" was second only to "Transportation," residents' satisfaction in "Environment" has a large influence on "Comprehensive Evaluation."

(C) Although Isesaki City and its residents promoted environmental improvements throughout the merged municipality, we did not observe an increase in unity of residents" consciousness towards "Environment." We reached this conclusion because the variation coefficient of the evaluation score of "Environment" did not decrease during the 4 years after consolidation. Therefore, a longer period of time is required to increase the unity of residents' consciousness through environmental improvements. This coincides with the findings of prior literature [5], and it appears the 4-year period of this research is too short to reveal any increase in the unity of residents' consciousness. (D) Based on the results of this research, a merged municipality and its residents can contribute to an increase in residents' satisfaction in their new city by improving the environment throughout the merged municipality. However, in order for a merged municipality and its residents to increase the unity of residents' consciousness by improving the environment throughout the merged municipality, an extremely long period of time is required. Therefore, the future task of this research is to continue conducting surveys and analyses, and make clear any changes in residents' consciousness over a longer period. Furthermore, the future task of this research is to analyze the differences in residents' consciousness between the former municipalities.

\section{REFERENCES}

[1] Okusawa N., Saito T., Kogawa T., Amako S., Nishizawa A. and Morimoto A., "Discussion : The Actualities and Virtual Image of City Planning Areas," City planning review, vol. 53/No. 4, August, 2004, pp. 27-34.

[2] Hashimoto T. and Yuzawa A., "Research on the regional gap of city planning area and residents consciousness after consolidation of municipalities : A case study on Isesaki City, Gunma Prefecture,” Journal of the City Planning Institute of Japan, No. 40-3, October, 2005, pp. 91-96.

[3] Endo R., Nakai N. and Nakanishi M., "Influences of municipal name change by consolidation on community consciousness : Case study on Sasayama City, Hyogo Prefecture,” Journal of the City Planning Institute of Japan, No. 39, October, 2004, pp. 319-324.

[4] Hashimoto T. and Yuzawa A., "Research on the regional gap of city planning area and administration consciousness after consolidation of municipalities : A case study on 160 cities with population above 50,000," Journal of the City Planning Institute of Japan, No. 41-3, October, 2006, pp. 601-606.

[5] Ministry of Internal Affairs and Communications, "Evaluation, validation and analysis of mergers," Report of the merger in Japan, June, 2008, pp.64-66. (http://www.soumu.go.jp/gapei/sicyouson_kenkyuuka i_mokuji.html)

[6] Tsukada S. and Yuzawa A., "Examination about the Evaluation Structure of the Basic Park caught from Residents Consciousness," Journal of the City Planning Institute of Japan, No. 37, October, 2002, pp. 907-912.

[7] Tsukada S. and Yuzawa A., "A Study of the Evaluation Structure and Attractive Factors of Large-Scale Park caught from User's Consciousness : A case Study in Maebashi City,” Journal of the City Planning Institute of Japan, No. 39, October, 2004, pp. 193-198.

[8] Tsukahara M., Fujita M. and Yamaoka S., "Analysis on Resident's Consciousness to WTP for the Community Zone Project Considering Mutual Relationship among Economic Values of Environmental Quality,” Journal of the City Planning Institute of Japan, No. 39, October, 2004, pp. 535-540.

[9] Tsukada S., Morita T. and Yuzawa A., "A Study on Evaluation of Shikishima Park as Change of the Spatial Characteristic and the Original Design,” Journal of the Japanese Institute of Landscape Architecture, No. 72(5), August, 2009, pp. 849-854.

International Journal of GEOMATE, June, 2012, Vol. 2, No. 2 (Sl. No. 4), pp. 235-240

MS No.3h received January 30, 2012, and reviewed under GEOMATE publication policies.

Copyright (C) 2012, International Journal of GEOMATE. All rights reserved, including the making of copies unless permission is obtained from the copyright proprietors. Pertinent discussion including authors' closure, if any, will be published in the June 2013 if the discussion is received by Dec. 2012.

Corresponding Author: Takashi Hashimoto 